\title{
Clearance of technetium-99m-DTPA and HRCT findings in the evaluation of patients with Idiopathic Pulmonary Fibrosis
} Katerina M Antoniou1 ${ }^{1}$, Katerina Malagari², Nikolaos Tzanakis', Kostas Perisinakis ${ }^{3}$, Emmanouil K Symvoulakis ${ }^{1}$, Nikolaos Karkavitsas ${ }^{3}$, Nikolaos M Siafakas ${ }^{1}$ and Demosthenes Bouros*4

\begin{abstract}
Address: ${ }^{1}$ Department of Thoracic Medicine, University Hospital of Heraklion Crete, Greece, ${ }^{2}$ Department of Radiology, Medical School University of Athens, Greece, ${ }^{3}$ Department of Nuclear Medicine, Medical School University of Crete, Greece and ${ }^{4}$ Department of Pneumonology, Democritus University of Thrace, Alexandroupolis, Greece

Email: Katerina M Antoniou - katerinaantoniou@yahoo.gr; Katerina Malagari - k.antoniou@rbht.nhs.uk;

Nikolaos Tzanakis - tzanakis@med.uoc.gr; Kostas Perisinakis - perisina@med.uoc.gr; Emmanouil K Symvoulakis - symvouman@yahoo.com;

Nikolaos Karkavitsas - pneumon@med.uoc.gr; Nikolaos M Siafakas - siafak@med.uoc.gr; Demosthenes Bouros* - bouros@med.duth.gr

* Corresponding author
\end{abstract}

Published: 16 February 2006

BMC Pulmonary Medicine 2006, 6:4 doi:10.1 I86/147I-2466-6-4

This article is available from: http://www.biomedcentral.com/I47/-2466/6/4

(C) 2006 Antoniou et al; licensee BioMed Central Ltd.

This is an Open Access article distributed under the terms of the Creative Commons Attribution License (http://creativecommons.org/licenses/by/2.0), which permits unrestricted use, distribution, and reproduction in any medium, provided the original work is properly cited.
Received: 15 July 2005

Accepted: 16 February 2006

\begin{abstract}
Background: Clearance of inhaled technetium-labeled diethylenetriamine pentaacetate ${ }^{999 \mathrm{mTc}}$ DTPA) is a marker of epithelial damage and an index of lung epithelial permeability. The aim of this study was to investigate the role of $99 \mathrm{mTc}$-DTPA scan in patients with Idiopathic Pulmonary Fibrosis (IPF). Our hypothesis is that the rate of pulmonary $99 \mathrm{mTc}$-DTPA clearance could be associated with extent of High Resolution Computed Tomography (HRCT) abnormalities, cell differential of bronchoalveolar lavage fluid (BALF) and pulmonary function tests (PFTs) in patients with IPF.
\end{abstract}

Methods: We studied prospectively 18 patients ( 14 male, 4 female) of median age 67yr (range 55$8 \mathrm{I}$ ) with histologically proven IPF. HRCT scoring included the mean values of extent of disease. Mean values of these percentages represented the Total Interstitial Disease Score (TID). DTPA clearance was analyzed according to a dynamic study using a Venticis II radioaerosol delivery system.

Results: The mean (SD) TID score was $36 \pm 12 \%, 3$ patients had mild, II moderate and 4 severe TID. Abnormal DTPA clearance half-time $\left(t_{1 / 2}<40 \mathrm{~min}\right)$ was found in $17 / 18$ (94.5\%) [mean (SD) 29.1 $\pm 8.6 \mathrm{~min}$. TID was weakly correlated with the DTPA clearance $(r=-0.47, p=0.048)$ and with $\%$ eosinophils $(r=0.475, p=0.05)$. No correlation was found between TID score or DTPA and PFTs in IPF patients.

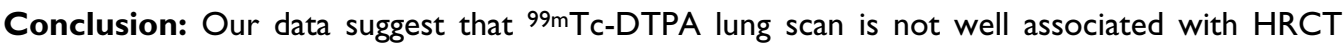
abnormalities, PFTs, and BALF cellularity in patients with IPF. Further studies in large scale of patients are needed to define the role of this technique in pulmonary fibrosis.

\section{Background}

Clearance of inhaled technetium-labeled diethylenetri- amine pentaacetate ( $99 \mathrm{mTc}$-DTPA) is an index of lung epithelial permeability $[1,2]$. The technique is non invasive, 
relatively inexpensive with a low radiation, and easy to perform using standard equipment in clinical nuclear medicine department [3].

Abnormal $99 \mathrm{mTc}$-DTPA has been found in several interstitial lung diseases $[4,5]$. It has been used as a marker of alveolar inflammation in sarcoidosis [4] and could potentially be used as a predictor of disease progression in idiopathic pulmonary fibrosis (IPF) [5]. In interstitial lung disease (ILD), active inflammation in the lower respiratory tract results in lung injury and fibrosis. On the contrary, recent data suggests that inflammation does not play a pivotal role in IPF [6]. Evidence suggests that epithelial injury, even in the absence of inflammation is sufficient to stimulate the development of fibrosis [6].

High-resolution computed tomography (HRCT) has diagnostic and prognostic value, and should be a part of the initial evaluation of ILD [7]. The extent of IPF on HRCT correlates roughly with severity of functional impairment (i.e, FVC and DLCO [8].

The objective of this study was to explore the role of $99 \mathrm{mTc}$ DTPA scanning in a well-defined population of IPF patients. In addition, our aim was to determine whether DTPA clearance is correlated with HRCT score, BALF differential cell counts and pulmonary function tests (PFTs).

\section{Methods \\ Patients}

Eighteen consecutive IPF patients who were investigated at our departments were enrolled in the study. The diagnosis of IPF was based on recently established criteria [9] and confirmed by lung biopsy with video-assisted thoracoscopic surgery (VATS). The histologic appearance was that of usual interstitial pneumonia (UIP) and all patients were newly diagnosed.

All patients (14 male, 4 female) of median age $67 \mathrm{yr}$ (range, 55-81), were studied prospectively. Patients were excluded from the study if they were current smokers (cessation of smoking at least 6 months prior to the measurement of DTPA clearance was a prerequisite for the enrollment).

\section{Spirometry}

Spirometry was performed with a computerized system (MasterLab, Jaeger 2.12, Germany). The measurement was performed using standard protocols according to American Thoracic Society (ATS) guidelines [10]. Subjects did not use short acting bronchodilators within 12 hours prior to the measurements. The best of three consecutive measurements was chosen.

\section{HRCT in IPF patients}

The HRCT slices were evaluated at five predetermined levels: the aortic arch, the tracheal carina, the pulmonary hilar, the pulmonary venous confluence, and $1-2 \mathrm{~cm}$ above the right hemidiaphragm. The scans were performed with $1 \mathrm{~mm}$ thickness and 1 to 2 sec scanning time during breath holding at end inspiration. High spatial frequency algorithm was used and images were read at window levels appropriate for pulmonary parenchyma (level600 to-700 Hounsfield units; window 1500-1600).

HRCT scoring in IPF patients included extent of disease at each of the above mentioned levels at the level of $5 \%$ using a visual method of assessment similar to that used previously by the same [11] and other investigators [8,1215]. Two experienced readers, first independently without any knowledge of the clinical and functional findings and subsequently- in cases in which there were discrepancieswith consensus, examined the HRCT scans.

HRCT scoring included extent of overall involvement of lung parenchyma at each HRCT slice at the nearest 5\% (range 0-100) using a visual method of assessment similar to that used previously by other investigators $[8,11$ 15]. The total interstitial disease score (TIDs) was calculated by the sum of all the above mentioned percentages divided by five-the number that represented the number of the slices evaluated. Interestingly, scores from the five HRCT slices were summed and divided by the total number of slices to calculate the average extent score for each of the variables. Similar methods of scoring have been used by Staples and coworkers [12], Lee and coworkers [13] and Wells and co-workers [8,15]. Lung parenchyma involvement was classified as $0-20 \%$ : mild (grade 1), 21-40\%: moderate (grade 2), >40\%: severe (grade 3 ). The classification of severity of disease in mild, moderate and severe is somehow arbitrarily made based on the TID obtained from the above calculations.

\section{9m Tc-DTPA scan}

An aerosol of Tc-99m diethylenetriamine pentaacetate (DTPA) was produced using a Venticis II radioaerosol delivery system (CIS bio international, Cedex, France). The radioaerosol was administered to patients for $4 \mathrm{~min}$ utes. A dynamic study consisting of 30 one-minute frames were then acquired by a GE Millennium MPS $\gamma$-camera (GE, Milwuakee, Wisconsin, USA).

Regions of interest (ROI) were identified on either lung and a background ROI was set. Background subtraction was employed and an exponential fit of the clearance of each lung was derived starting from the frame with peak activity. The half-time of clearance was estimated in minutes for each lung and the average value was obtained. A clearance half-time of $<40 \mathrm{~min}$ was regarded as abnormal. 
Table I: IPF patients characteristics

\begin{tabular}{ll}
\hline Sex $($ Male/Female) & $14 / 4$ \\
Age, range, $y r($ mean \pm SD) & $55-81(67 \pm 7.3)$ \\
FVC\% pred, $x \pm$ SD & $76.1 \pm 11.5$ \\
FEV $\%$ pred, $x \pm$ SD & $81.9 \pm 14.5$ \\
TLC\% pred, $x \pm$ SD & $62.7 \pm 9.4$ \\
TLCO\% pred, $x+S D$ & $68.0 \pm 12.2$
\end{tabular}

A clearance half-time of less than $20 \mathrm{~min}$ ( $50 \%$ of normal) was categorized as very rapid $[4,5,16]$.

\section{Bronchoalveolar lavage}

Fiberoptic bronchoscopy with BAL was performed as part of routine clinical management, according to recommended guidelines and previous reports [17].

Subjects were premedicated with atropine $0.5 \mathrm{mg} \mathrm{IM}$, and the airways were anesthetized by inhalation of $4 \%$ xylocaine. Supplemental oxygen was administered during and immediately after the procedure. Oxygen saturation and ECG tracings were monitored during the procedure. After the administration of $2 \%$ topical xylocaine, the bronchoscope was inserted transnasally and, after inspection of segmental orifices, it was wedged according to a standard protocol in the middle lobe or the lingula. Aliquots of 60 $\mathrm{ml}$ of sterile normal saline previously warmed to $37^{\circ} \mathrm{C}$ instilled through the bronchoscope, and the fluid was retrieved by mechanical suction. The standard introduction volume was $180 \mathrm{ml}$ and the recovery volume $>60 \%$ in all cases. The cells were recovered by gentle aspiration.

Slide preparations for differential percentage counting of cells were made in a cytocentrifuge (Aero spray, Wescor, USA) using 50- $\mu \mathrm{L}$ aliquots of the lavage cell suspensions. Two slides were stained with May-Grunewald-Giemsa stain. Differential counts were made by two independed observers for a minimum count of 500 nucleated non squamous cells. Visually identified squamous epithelial cells were not included in the total cell count. Additionally, $300 \mu \mathrm{L}$ of BALF were processed for flow cytometric analysis.

All the above investigations (spirometry, bronchoalveolar lavage fluid, HRCT and DTPA scan) are incorporated in the routine follow-up of our hospital. An ethical approval was not necessary to be asked.

\section{Statistical analysis}

All analyses were performed using the statistical software Stats-Disect for Windows version 1.8.9 (Camcode, Cambridge, UK). Results are expressed as mean $+1 \mathrm{SD}$, or median (range), unless other indicated. The KolmogorovSmirnof test for normality was applied to examine data distribution. Differences between the two groups of sub-
Table 2: Mean \pm SD of total and percentage $( \pm$ SD) of differential cell counts in BALF in I 8 IPF patients.

\begin{tabular}{ll}
\hline Cell Type & \\
\hline Total cell count, $\times 105 / \mathrm{mL}$ & $28.6 \pm 3.2$ \\
Macrophages,\% & $82.2 \pm 4.3$ \\
Lymphocytes,\% & $7.7 \pm 3.0$ \\
Neutrophils,\% & $6.23 \pm 2.2$ \\
Eosinophils, \% & $3.7 \pm 2.4$
\end{tabular}

jects were tested using the Mann-Whitney U test. Correlation between cell and physiological variables were analyzed using Spearman's rank correlation coefficient. A p value of $<0.05$ was considered as statistically significant.

\section{Results}

The demographic and clinical characteristics of the IPF patients are shown in table 1.

The mean (SD) TID score was $36 \pm 12 \%, 3$ patients had mild, 11 moderate and 4 severe TID. Abnormal DTPA clearance half-time $\left(t_{1 / 2}<40 \mathrm{~min}\right)$ was found in 17 of the18 (94.5\%) IPF patients [mean (SD) $29.1 \pm 8.6 \mathrm{~min}$ ].

A weak association was found between TID score and DTPA clearance $(r=-0.47, p=0.048)$ (Figure 1$)$. No correlation was found between TID score or DTPA and PFTs in IPF patients.

The total and the differential cell counts of BALF are shown in Table 2. TID score was weakly correlated with eosinophils $(\mathrm{r}=0.475, \mathrm{p}=0.05)$ (Figure 2$)$ and negatively with macrophages $(\mathrm{r}=-0.507, \mathrm{p}=0.03)$.

\section{Discussion}

This is the first study to systematically evaluate newly diagnosed IPF patients with biopsy proven histology of usual interstitial pneumonia (UIP), excluding the other clinical-pathologic entities of idiopathic interstitial pneumonias, comparing quantitatively the extent of abnormalities in the HRCT and 99mTc-DTPA clearance prospectively. We found that the $99 \mathrm{~m}$ Tc-DTPA clearance time is abnormal in almost all $(94.5 \%)$ of IPF patients. On the contrary, we failed to detect a strong correlation between HRCT TID score and 99mTc-DTPA clearance. An additional finding of this study is a weak linkage between TID score and eosinophils in BALF.

In a recent prospective study Mogulkoc et al. [16] evaluated the potential ability of $99 \mathrm{mTc}$-DTPA scanning in predicting survival in a large scale population of $106 \mathrm{IPF}$ patients. On the other hand, only $30 \%$ of them had histologically proven disease. The authors showed that the predictive value of this technique (in terms of survival) was lower than that of total lung capacity and DLCO. They 


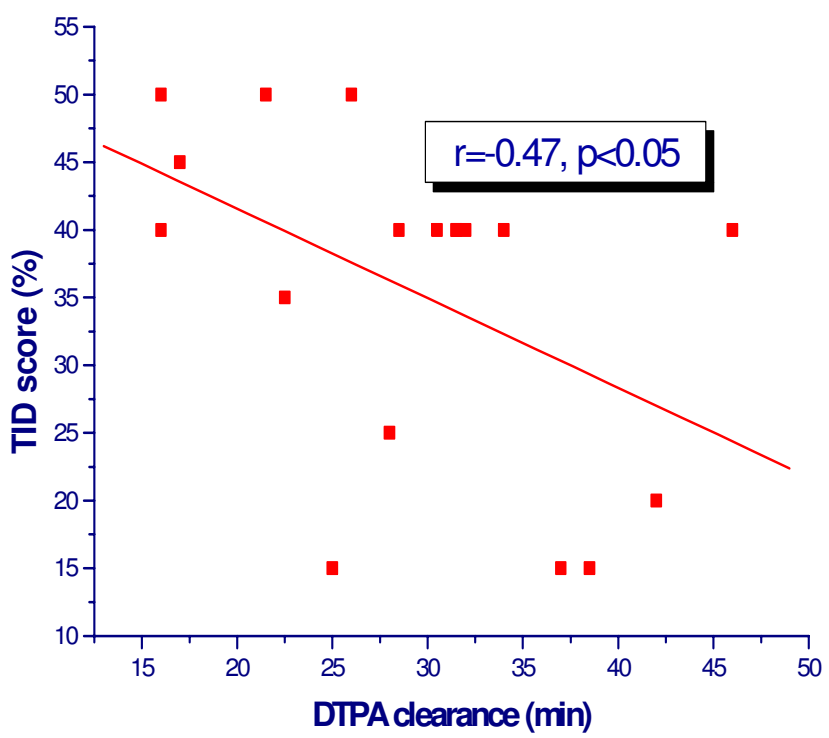

Figure I

Correlation of DTPA clearance and HRCT TID score in IPF patients.

also detected that the clearance values did not correlate with the HRCT scoreby using a both mono-exponential and bi-exponential analysis [16], in accordance with our data. In line with these findings, a recent published study has shown that clearance of inhaled ${ }^{99 m T c-D T P A}$ is not of value in following the progress of IPF [17]. Mura and coworkers did not detect any significant correlation between 99mTc-DTPA and functional tests or HRCT score [18]. DTPA scan has been used in the repertoire of investigations in a number of diffuse parenchymal diseases [19-25] but all of them were before the recent revision of the histological classification of IPF [26].

The specific mechanism of increased clearance time in IPF is still unclear but has been thought to be secondary to the stretching of epithelial junctions in the alveolar wall as a result of fibrotic traction or lymphocytic infiltration $[27,28]$. We speculate that the rapid clearance may occur across the bare basement membrane, denuded of epithelium, which has been demonstrated in ultrastructural studies of IPF [29].

We found no correlation between aerosol clearance and pulmonary function parameters, in agreement with the findings of previous studies [16,18-20]. Similarly, only a weak correlation between DTPA clearance and \% predicted TLCO was found in patients with sarcoidosis and scleroderma [21-23]. The consistent absence of a correlation may be because the impairment of pulmonary function parameters is a result of the maldistribution of ventilation and perfusion or loss of surface area, while the

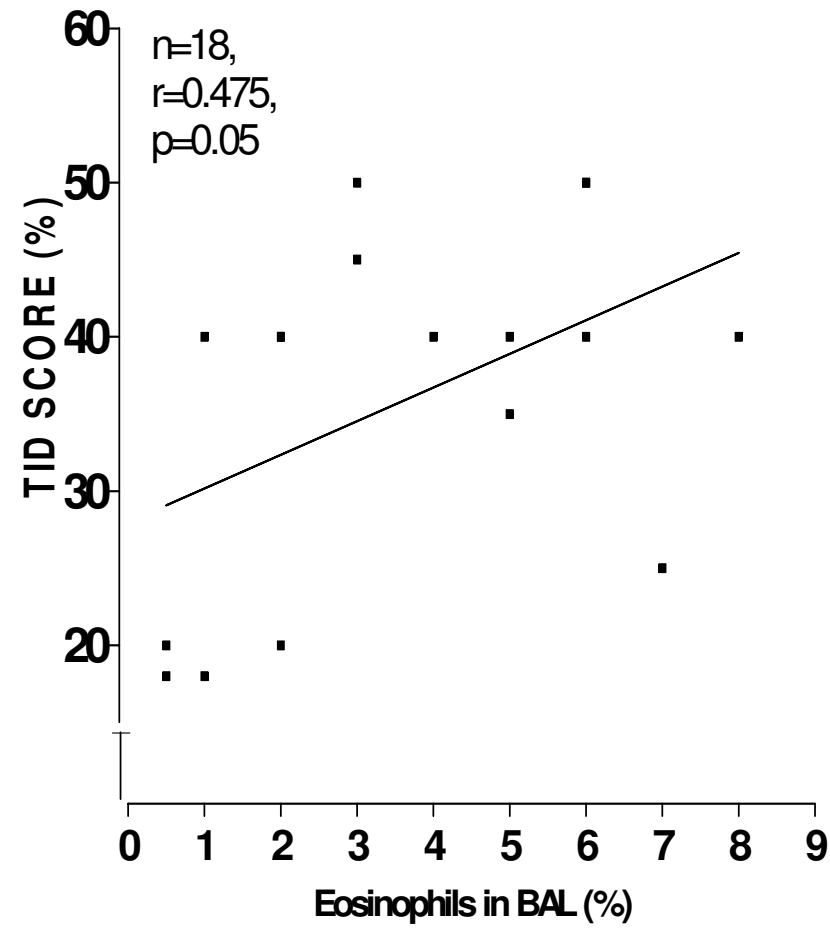

Figure 2

Correlation of HRCT TID score and \% of eosinophils in BALF.

increased rate of DTPA clearance is caused by increased junctional permeability in the alveolar capillary membranes [16].

Wells et al. reported that depression of TLCO and FVC were positively related to the extent of disease on the CT scan and that there were no independent relationships between functional indices and the pattern or distribution of disease on the CT scan $[8,15,30]$. We did not find similar correlation between TID score or DTPA and PFTs in our IPF population. We have used TID score in the evaluation of HRCT scans, which is a similar technique of estimating disease extent applied in previous studies $[8,11,16,30]$. In detail, this method of scoring is similar to that used by Staples and coworkers [12] and Lee and coworkers [13] represents a slight modification of the scoring system used by Wells and coworkers [8,15,30]. It was recently used by our radiologist in the evaluation of dyspnea in IPF [11]. One of the findings of the aforementioned study was that TIDs was significantly associated with FVC, FEV1, TLC and PaO2 [11]. On the other hand, in the studies of Staples [12] and Terriff [31], FVC was not correlated with the HRCT scores. Wells et al. found that the extent of fibrosing alveolitis and the presence of emphysema are independent determinants of functional impairment by using a multivariate analysis model [32]. This observation 
leads to the premese that quantification of disease severity using pulmonary function tests is often confounded by emphysema [32]. The above discrepancies among previous studies and the present results are difficult to explain but may be related to the variable course of the disease, to the fact that somewhat different methodologies have been used $[11,12,15,31,33]$ and also to the fact that some previous works included patients with interstitial lung disease associated with conditions such as connective tissue disorders $[12,15,34]$. In addition, we speculate that differences could be derived from the fact that we have not estimated the percentage of emphysema. Furthermore, Kazerooni and coworkers have used a different, in our opinion more complicated, HRCT scoring system [33], and demonstrated an excellent correlation between HRCT and pathology fibrosis score.

We found a moderately significant correlation of DTPA clearance with the visual score in HRCT in 18 patients with IPF. We could not overestimated these results because are based only on a limited number of subjects and on a correlation factor of -0.47 ; it should be supported by a follow-up study in order to investigate if the clearance of 99m-DTPA can actually predict the clinical course of IPF. Furthermore, a recent study demonstrated that clearance of 99m-DTPA, although abnormal in all subjects in presentation, was not a predictor of disease progression in IPF patients [17]. Additionally, Mogulkoc et coworkers showed that the predictive value of the aforementioned technique (in terms of survival) was lower than that of total lung capacity and DLCO, and the clearance values did not correlate with the HRCT score [17]. However, this study differs from ours in that it focuses on the resolution of the DTPA clearance into fast and slow components. Harrison et al. reported that when the CT scan is normal, abnormalities of BAL and/or DTPA clearance may indicate lung disease at a still earlier stage in patients with systemic sclerosis [24].

We also found a moderate correlation between BAL eosinophilia and HRCT TID score. It has been shown that excess neutrophils and/or eosinophils $(>5 \%)$ in the BALF have been associated with a higher likelihood of disease progression and a failure to respond to immunosuppression [9].

\section{Conclusion}

Our data suggest that at the moment there are not sufficient evidences to recommend the implementation of 99mTc-DTPA lung scan in the follow-up of IPF patients. Further prospective studies in a large scale and welldefined IPF population are necessary to define the role of this modern technique in the evaluation of pulmonary fibrosis.

\begin{abstract}
Abbreviations
99mTc-DTPA: inhaled technetium-labeled diethylenetriamine pentaacetate
\end{abstract}

IPF: Idiopathic Pulmonary Fibrosis

HRCT: High Resolution Computed Tomography

PFTs: pulmonary function tests

BALF: bronchoalveolar lavage fluid

TID: Total Interstitial Disease Score

\section{Competing interests}

The author(s) declare that they have no competing interests.

\section{Authors' contributions}

KMA, NMS and DB participated in the design and coordination of the study. KMA prepared the manuscript. KM carried out the HRCT scoring, NT carried out the Bronchoalveolar Lavage, KP and NK carried out the DTPA scans. NT and EKS carried out the statistical analysis. DB and NMS were invo;ved in revising the article for important intellectual content. All authors read and approved the final manuscript.

\section{Acknowledgements}

We are grateful to Drs Maltezakis Georgios, Lambiri Irini and Kostaki Aggeliki for enrolling patients in the study.

\section{References}

I. O'Brodovich H, Coates G: Pulmonary clearance of $99 \mathrm{mTc}$ DTPA: a noninvasive assessment of epithelial integrity. Lung 1987, 165:1-16.

2. Susskind H: Technetium-99m-DTPA aerosol to measure alveolar-capillary membrane permeability. I Nucl Med 1994, 35:207-9.

3. Smith RJ, Hyde RW, Waldman DL, Freund GG, Weber DA, Utell MJ, Morrow PE: Effect of pattern of aerosol inhalation on clearance of technetium-99m-labeled diethylenetriamine pentaacetic acid from the lungs of normal humans. Am Rev Respir Dis 1992, 145: I 109-16.

4. Chinet T, Dusser D, Labrune S, Collignon MA, Chretien J, Huchon GJ: Lung function declines in patients with pulmonary sarcoidosis and increased respiratory epithelial permeability to 99mTc-DTPA. Am Rev Respir Dis 1990, I41:445-9.

5. Wells AU, Hansell DM, Harrison NK, Lawrence R, Black CM, du Bois RM: Clearance of inhaled 99mTc-DTPA predicts the clinical course of fibrosing alveolitis. Eur Respir J 1993, 6:797-802.

6. Selman M, King TE Jr, Pardo A: Idiopathic Pulmonary Fibrosis: Prevailing and evolving hypotheses about its pathogenesis and implications for therapy. Ann Intern Med 200I, I34: I36-I5I.

7. Raghu G: Interstitial lung disease: a diagnostic approach. Are CT scan and lung biopsy indicated in every patient? Am J Respir Crit Care Med 1995, I 5 I:909-14.

8. Wells AU, Rubens MB, du Bois RM, Hansell DM: Functional impairment in fibrosing alveolitis: relationship to reversible disease on thin section computed tomography. Eur Respir J 1997, 10:280-5

9. American Thoracic Society: Idiopathic pulmonary fibrosis: diagnosis and treatment. International consensus statement. American Thoracic Society (ATS), and the European Respi- 
ratory Society (ERS). Am J Respir Crit Care Med 2000, I6 I(2 Pt I):646-64.

10. Standardization of Spirometry, 1994 Update. American Thoracic Society. Am J Respir Crit Care Med I 995, I 52(3): I I 07-36.

II. Papiris SA, Daniil ZD, Malagari K, et al: The Medical Research Council dyspnea scale in the estimation of disease severity in idiopathic pulmonary fibrosis. Respir Med 2005, 99:755-6I.

12. Staples CA, Muller NL, Ostrow D, et al.: Usual Interstitial Pneumonia: Functional and radiologic correlations. Radiology I987, 162:377-81.

13. Lee JS, Im JG, Ahn JM, Kim YM, Han MC: Fibrosing alveolitis: prognostic implication of ground-glass attenuation at high-resolution CT. Radiology 1992, I84(2):45|-4.

14. Muller NL, Mawson JB, Mathieson JR, Abboud R, Ostrow DN, Champion P: Sarcoidosis: correlation of extent of disease at CT with clinical, functional, and radiographic findings. Radiology 1989, I $71(3): 613-8$

15. Wells AU, Hansell DM, Rubens MB, et al.: The predictive value of appearances on thin-section computed tomography in fibrosing alveolitis. Am J Respir Crit Care Med 1993, I 48: 1076-82.

16. Mogulkoc N, Brutsche MH, Bishop PW, Murby B, Greaves MS, Horrocks AW, Wilson M, McCullough C, Prescott M, JJ Egan: Pulmonary $(99 \mathrm{~m}) \mathrm{Tc}$-DTPA aerosol clearance and survival in usua interstitial pneumonia (UIP). Thorax 200I, 56(I 2):916-23.

17. Technical recommendations and guidelines for bronchoalveolar lavage (BAL). Report of the European Society of Pneumology Task Group. Eur Respir J 1989, 2(6):561-85.

18. Mura M, Belmonte G, Fanti S, Pacilli AM, Fasano L, Zompatori M, Schiavina $M$, Fabbri $M$ : Does technetium-99m diethylenetriaminepentaacetate clearance predict the clinical course of idiopathic pulmonary fibrosis? Can Respir / 2004, II:477-9.

19. Wang S], Kao $\mathrm{CH}$ : The alveolar permeability in patients with diffuse infiltrative lung disease detected by Tc-99m DTPA radioaerosol inhalation lung scintigraphy and the relationships with the pulmonary function test. Zhonghua $Y_{i} X_{\text {Xue }} \mathrm{Za} Z \mathrm{Zhi}$ (Taipei) 1995, 56:264-9.

20. Anazawa $Y$, Isawa T, Teshima T, Miki M, Motomiya M: [Pulmonary epithelial permeability in normal subjects and patients with idiopathic interstitial pneumonia]. Nihon Kyobu Shikkan Gakkai Zasshi 1991, 29:1439-43.

21. Kon OM, Daniil Z, Black CM, du Bois RM: Clearance of inhaled technetium-99m-DTPA as a clinical index of pulmonary vascular disease in systemic sclerosis. Eur Respir J 1999, 13:133-6.

22. Diot $E$, Giraudeau B, Maillot F, Diot P: Decrease in DL, CO in systemic sclerosis correlates with acceleration of DTPA clearance. Eur Respir J 1999, 14:728-9.

23. Jacobs MP, Baughman RP, Hughes J, Fernandez-Ulloa M: Radioaerosol lung clearance in patients with active pulmonary sarcoidosis. Am Rev Respir Dis 1985, 13 1:687-9.

24. Harrison NK, Glanville AR, Strickland B, Haslam PL, Corrin B, Addis B], Lawrence R, Millar AB, Black CM, Turner-Warwick M: Pulmonary involvement in systemic sclerosis: the detection of early changes by thin section CT scan, bronchoalveolar lavage and 99mTc-DTPA clearance. Respir Med 1989, 83:403-I4.

25. Yeh SH, Liu RS, Wu LC, Peng NJ, Lu JY: 99Tcm-HMPAO and 99Tcm-DTPA radioaerosol clearance measurements in idiopathic pulmonary fibrosis. Nucl Med Commun 1995, 16:140-4.

26. Bouros D: Current classification of idiopathic interstitial pneumonias. Monaldi Arch Chest Dis 2000, 55:450-4.

27. Chopra SK, Taplin GV, Tashkin DP, Elam D: Lung clearance of soluble radioaerosols of different molecular weights in systemic sclerosis. Thorax 1979, 34:63-7.

28. Labrune S, Chinet T, Collignon MA, Barritault L, Huchon GJ: Mechanisms of increased epithelial lung clearance of DTPA in diffuse fibrosing alveolitis. Eur Respir J 1994, 7:651-6.

29. Corrin B, Dewar A: Pathogenesis of idiopathic interstitial pulmonary fibrosis. Ultrastruct Pathol 1996, 20:369-7I.

30. Wells AU, King AD, Rubens MB, Cramer D, du Bois RM, Hansell DM: Lone cryptogenic fibrosing alveolitis: a functional-morphologic correlation based on extent of disease on thin-section computed tomography. Am J Respir Crit Care Med 1997, I 55: 1367-1375.

31. Terriff BA, Kwan SY, Chan-Yeung MM, Muller NL: Fibrosing alveolitis: chest radiography and $C T$ as predictors of clinical and functional impairment at follow-up in $\mathbf{2 6}$ patients. Radiology 1992, I84:445-9.
32. Wells AU, Desai SR, Rubens MB, Goh NS, Cramer D, Nicholson AG, Colby TV, du Bois RM, Hansell DM: Idiopathic pulmonary fibrosis: a composite physiologic index derived from disease extent observed by computed tomography. Am J Respir Crit Care Med 2003, 167:962-9.

33. Kazerooni EA, Martinez FJ, Flint A, et al:: Thin-section CT obtained at $10-\mathrm{mm}$ increments versus limited three-level thin-section CT for idiopathic pulmonary fibrosis: correlation with pathologic scoring. AJR Am J Roentgenol 1997, 169:977-83.

34. Wells AU, Hansell DM, Rubens MB, Cullinan P, Haslam PL, Black CM, Du Bois RM: Fibrosing alveolitis in systemic sclerosis. Bronchoalveolar lavage findings in relation to computed tomographic appearance. Am J Respir Crit Care Med 1994, I 50:462-8.

\section{Pre-publication history}

The pre-publication history for this paper can be accessed here:

http:/www.biomedcentral.com/1471-2466/6/4/prepub
Publish with Biomed Central and every scientist can read your work free of charge

"BioMed Central will be the most significant development for disseminating the results of biomedical research in our lifetime. "

Sir Paul Nurse, Cancer Research UK

Your research papers will be:

- available free of charge to the entire biomedical community

- peer reviewed and published immediately upon acceptance

- cited in PubMed and archived on PubMed Central

- yours - you keep the copyright
BioMedcentral 